\title{
Formas pronominales de tratamiento y cortesía en el habla de Tunja, Colombia ${ }^{1}$
}

\author{
Pronoun forms and courtesy in spoken \\ language in Tunja, Colombia
}

Gloria Smith Avendaño de Barón ${ }^{2}$

Resumen

Este artículo presenta resultados de una investigación orientada hacia los siguientes propósitos: determinar la frecuencia de uso de las formas pronominales de tratamiento cortés sumercé, usted y tú, según variables sociales de género, edad y nivel de instrucción en hablantes de Tunja; describir las variaciones sociodiscursivas y explicar la relación de ese uso con la cortesía. Se utilizó la metodología del Proyecto para el Estudio Sociolingüístico del Español de España y de América (PRESEEA) y la muestra se conformó con 54 hablantes. Los resultados indican que la forma pronominal más empleada en Tunja es sumercé, para expresar cordialidad y afecto, seguida de usted y tú; las mujeres y los hombres de distintas generaciones y niveles de instrucción alternan el empleo de esas tres formas en el contexto de discursos de tipo narrativo, descriptivo, argumentativo y expositivo.

\section{Palabras clave}

Sumercé, usted, tú, cortesía, variación sociodiscursiva.

\section{Abstract}

This article presents the results of a research project whose aims were the following: to determine the frequency of the use of pronoun forms in polite treatment sumercé, usted and tú, according to differences in gender, age and level of education, among speakers in Tunja; to describe the sociodiscursive variations and to explain the relationship between usage and courtesy. The methodology of the Project for the Sociolinguistic Study of Spanish in Spain and in Latin America (PRESEEA) was used, and a sample of 54 speakers was taken. The results indicate that the most frequently used pronoun in Tunja to express friendliness and affection is sumercé, followed by usted and tú; women and men of different generations and levels of education alternate the use of these three forms in the context of narrative, descriptive, argumentative and explanatory speech.

Key words

Sumercé, usted, tú, courtesy, sociodiscursive variation.

Artículo recibido el 31 de octubre de 2013 y aprobado el 7 de febrero de 2014

1 Subproyecto desarrollado en el seno del Grupo de Investigación para el Estudio Sociolingüístico del Caribe e Hispanoamérica (GIESCAH).

2 Universidad Pedagógica y Tecnológica de Colombia, Tunja, Colombia. Correo electrónico: gloria.avendano@uptc.edu.co 
Universidad Pedagógica Nacional

Facultad de Humanidades

Este trabajo hace parte del proyecto macro intitulado El español hablado en Tunja: materiales para su estudio (Calderón, 2011), concebido con el fin de mostrar el funcionamiento sociolingüístico y pragmático de la lengua de esta comunidad; los hallazgos entrarán a formar parte de los futuros macroestudios tendientes a caracterizar el español que se habla en el mundo hispano. En el presente artículo se exponen los resultados de un subproyecto orientado básicamente a describir y explicar, de modo experimental, el funcionamiento de la cortesía positiva y negativa a través del uso de formas pronominales de tratamiento sumercé, usted y tú, pues hasta ahora no se conocen investigaciones que identifiquen, analicen y expliquen, desde la sociolingüística y la pragmática, la alternancia en el uso de formas pronominales de tratamiento en la comunidad de habla de Tunja. Cabe indicar que los trabajos de este tipo permiten visibilizar la riqueza expresiva de los hablantes hispanoamericanos y reconocer el aporte de cada variación a la vigencia de la lengua española. Las formas pronominales de tratamiento, en el contexto de la cortesía, han sido estudiadas por varios pensadores de las ciencias del lenguaje; veamos solo unas cuantas investigaciones.

Algunas compilaciones de Diana Bravo y Antonio Briz en Pragmática sociocultural: estudios sobre el discurso de cortesía en español (2004):

"Formas de cortesía en la Segunda Celestina", de Rosario Navarra G. (pp. 213-226). Aquí se realiza un análisis completo de la cortesía pronominal presente en los diálogos de esa obra literaria. El trabajo se apoya en los estudios de Rafael Lapesa (1991 y 2000) y de Beatriz Fontanella (1999).

"Tratamientos y cortesía en la elaboración de fuentes documentales de la etapa fundacional de la provincia de Mérida (Venezuela)", de Micaela Carrera de la R. y Alexandra Álvarez (pp. 227-243). Las autoras analizan las fórmulas de tratamiento en cuatro documentos del siglo XVI (dos cartas particulares y dos documentos públicos), las investigadoras hallaron que en dichos textos se emplea la fórmula vuestra merced para demostrar un alto grado de cortesía y, con ello, lograr algún beneficio del receptor.

"Formas de tratamiento de dos obras de teatro del siglo XX: Historia de una escalera y Bajarse al Moro", de Juan Manuel Pedroviejo E. (pp. 245-261). Pedroviejo descubre que en esas obras de teatro del siglo XX, las fórmulas de tratamiento tanto pronominales como nominales varían y adquieren diferentes valores en el transcurso de dicho siglo porque en ellas influyen factores temporales, sociales, de género y de edad.

Otro trabajo relevante es el de Mireya Cisneros E. intitulado "Grados de cortesía en el uso de pronombres personales de segunda persona singular", compilado en Diana Bravo: Estudios de la (des) cortesía en español. Categorías conceptuales y aplicaciones a corpora orales y escritos (2005, pp. 221244). Mireya expone un recorrido histórico para observar la evolución de este tipo de pronombres y, a la vez, analizar la gradación de la cortesía implícita en las expresiones lingüísticas: tú, vos, vuestra merced y usted.

Cabe destacar también las siguientes investigaciones:

"Sumercé una forma de tratamiento usada por niños, jóvenes y adultos del municipio de PaipaBoyacá", de Claudia Peralta M. (2006). En este trabajo se encontró que los hablantes de ese municipio otorgan un alto grado de afectividad a la forma de tratamiento sumercé que se emplea con mayor frecuencia para dirigirse a los abuelos, padres y tíos, y en menor porcentaje para las personas de género contrario. Sumercé es utilizado, especialmente, en las reuniones familiares.

"Formas de tratamiento en Costa Rica durante la Colonia", de Miguel A. Quesada, citado por Claudia Peralta M. (2006). Este estudio presenta un análisis descriptivo y diacrónico de algunas variantes lingüísticas del español. La fuente de esta investigación se encuentra en documentos no literarios de Costa Rica que datan de los años 1600 a 1805; entre ellos hay testamentos, juicios, peticiones, cartas privadas, informes y temas eclesiásticos. 
Observamos que los anteriores trabajos, salvo el de Claudia Peralta M., se centran en el estudio de las formas pronominales de tratamiento y la cortesía en documentos escritos, literarios y no literarios, lo cual es plausible, dado que ellos revelan el habla de unas comunidades en un tiempo determinado de la historia.

Ahora bien, en nuestra investigación se describió y se analizó el uso de tres formas pronominales de tratamiento en la comunidad de habla de Tunja (sumercé, usted y tú), y se explicó ese uso en relación con la cortesía, en contextos de interacción oral; cabe mencionar que el corpus se constituyó con muestras de personas que viven actualmente en esta ciudad. Para abordar este trabajo nos apoyamos en los siguientes planteamientos teóricos de algunos estudiosos de la sociolingüística y de la pragmática: interacción comunicativa, conversación, cortesía (positiva y negativa), variación en los niveles de la lengua (variación sociodiscursiva), formas pronominales de tratamiento y cortesía, y variables sociales que rigen las formas pronominales de tratamiento.

\section{Interacción comunicativa}

La interacción comunicativa se concibe como aquellos eventos de carácter lingüístico y no lingüístico (gestos, sonrisas, miradas, movimientos y posturas del cuerpo, etc.) en los que dos o más personas llevan a cabo una dialógica en la que ejercen como actores de la comunicación, de manera simultánea. Van Dijk (1983) la define como una serie de acciones en las que varios individuos se ven involucrados alternativa o simultáneamente como agentes; es decir, el hablante pasa a ser oyente y el oyente, hablante. Así, una interacción se configura por una acción mancomunada, ya sea conflictiva o cooperativa, en la que se relacionan varios actores (Vión, 1992, citado por Portolés, 2007); la interacción comunicativa se concreta en lo que comúnmente llamamos conversación.

\section{La conversación}

Es un modo de ser de la interacción comunicativa entre seres humanos; es una manifestación social, elemental y cotidiana del uso del lenguaje; hace parte de las diversas situaciones en las que un hablante alterna con otro en el proceso comunicativo. Tusón (1997) señala que el lenguaje primeramente se expresa mediante la conversación, $\mathrm{y}$ a través de este acto puramente humano, los individuos se relacionan entre sí, procuran lograr sus propósitos o, también, es posible romper vínculos sociales. La conversación es un proceso, una interacción social, psicológica y lingüística con una estructura interna, conversamos haciendo uso de una lengua que constituye una de las múltiples expresiones del lenguaje humano (Moreno, 2005).

Van Dijk (1983), por su parte, afirma:

La conversación es la 'forma fundamental' de la interacción oral y a la vez un componente esencial del trato cotidiano - es decir: no específico ni especializado- de las personas en situaciones sociales [...], es una forma especial de interacción lingüística. (pp. 239, 257)

Indudablemente, a la gran mayoría de las personas nos agrada conversar, dado que somos seres sociales por naturaleza; sabido es que la sociedad del conocimiento ha evolucionado gracias a las conversaciones que anteceden la búsqueda y construcción de saberes, hoy más que nunca logrados mediante el trabajo colectivo.

\section{Características de la conversación}

De acuerdo con Portolés (2007), este tipo de discurso se caracteriza por ser:

- Oral: se articula por medio del canal fónico, en oposición a una correspondencia epistolar o a un chat, que son textos escritos.

- Dialogal: comporta una sucesión de intervenciones, en oposición a los discursos monologales.

- Inmediato: ocurre en la coordenada espaciotemporal aquí-ahora-ante ti, diferente de un 
Universidad Pedagógica Nacional

Facultad de Humanidades

informativo radial o televisivo, que acostumbran a ser ahora, pero no aquí y ante ti, o un programa en diferido que ni siquiera es ahora.

- Dinámico: permite el cambio de roles entre los interlocutores (de hablante a oyente, de oyente a hablante). Dicha alternancia se produce en la conversación de una forma no predeterminada, en oposición a un debate televisado, por ejemplo, en el que existen unas reglas conocidas previamente para la toma del turno de habla.

- Cooperativo: se concreta junto a otro o a otros, ocurre entre dos o más personas.

Toda conversación contiene los siguientes elementos: un sistema verbal, un sistema paralingüístico - no verbal, pero que es vocálico-, y dos sistemas que no son verbales ni tampoco vocálicos: kinesia y proxemia. A continuación, explicaremos, someramente, los tres últimos a partir de Poyatos (1994), citado por Portolés (2007, pp. 70-73):

- El paralenguaje. Corresponde a las cualidades no verbales modificadoras de la voz, y sonidos y silencios independientes con que apoyamos o contradecimos los estímulos verbales y kinésicos simultáneos o alternantes. Son paralenguajes, entre otros, fenómenos prosódicos como el distinto uso del timbre, de la intensidad, velocidad de habla (rápida o lenta), duración silábica (titubeo), la risa, el llanto, el suspiro y algunas interjecciones ( juuuu, , para aludir a un tiempo bastante extenso; ibfffi, para manifestar alivio).

- La kinesia. Referida a los movimientos y posiciones de base psicomuscular conscientes o inconscientes, aprendidos o somatogénicos, de percepción visual, audiovisual y táctil o cinestésica que, aislados o combinados con la estructura lingüística y paralingüística, poseen valor comunicativo intencionado o no. Son kinésicas las siguientes expresiones: gestos (que involucran la cabeza, la cara, los ojos, los brazos, las piernas y otras partes del cuerpo); las maneras, que constituyen las for- mas en que se realizan los gestos o las posturas, por ejemplo, en señal de afecto, saludar dando una mano y colocando la otra sobre la del interlocutor; las posturas, que serían las posiciones estáticas, pues la forma en la que se realizan serían las maneras, posiciones de las piernas y de los brazos.

La relevancia de este elemento kinésico y paralingüístico se refleja en esta recomendación hecha a un entrevistador (Portolés, 2007):

[...] ha de saber escuchar y hacerlo visiblemente para dar confianza al personaje [informante] y que se explaye sin nerviosismos. Las preguntas serán formuladas con palabras sencillas. Un buen truco para soltar en la entrevista frases ciertamente impertinentes se basa en hacerlo con la sonrisa en los labios, buscando la complicidad. El entrevistado se verá obligado igualmente a contestar y, luego, en la transposición de la charla al papel impreso, el diálogo adquirirá mayor contundencia e interés. (p. 72)

En este caso, el entrevistado responde a un estímulo tanto verbal como kinésico, pero verá en la entrevista escrita, una respuesta adaptada únicamente al componente verbal.

- La proxemia. Alude a la forma como se sitúan los hablantes dentro del espacio físico en una interacción comunicativa; la distancia y la posición entre los participantes de una conversación pueden variar según la cultura, el tipo de actividad y la relación afectiva o de confianza entre los interlocutores.

Nuestra investigación se centró en el sistema verbal-oral, específicamente, en el uso de tres formas pronominales de tratamiento, ya citadas, en los contextos de conversaciones cotidianas y entrevistas semidirigidas.

\section{La conversación cotidiana}

El lenguaje es interactivo, se ubica en su dimensión social y actitudinal, puesto que fundamenta y rige la conducta psicosocial de la persona. Por consiguiente, a través de la interacción comunicativa, especialmente, de la conversación, se muestra el 
manejo de una lengua, los saberes, el conocimiento del mundo, las ideologías y las formas de pensar; se insinúan emociones, pasiones, sentimientos (amistad, amor, cariño, empatía, desprecio, afectos, desafectos), relaciones de jerarquía social entre los interlocutores y se revelan comportamientos, unas veces en forma abierta y sincera y otras de manera aparente. Sin duda, generalmente, todos intentamos seguir algunos principios de cooperación en nuestras conversaciones diarias, pero solo para manifestar sentimientos de cortesía hacia nuestro interlocutor y no para garantizar una charla perfecta y fructífera. ${ }^{3}$

Van Dijk (1983) afirma que las conversaciones cotidianas típicas son aquellas que tienen lugar en contextos informales: durante el desayuno, en el tranvía, por la calle, etc. No hay limitaciones generales para las conversaciones cotidianas, en principio, cualquier persona puede participar, no están planeadas con anterioridad, su objeto no está fijado a priori - por lo menos no en detalle-, y se pueden sostener en distintos contextos con varias funciones posibles. No obstante, cada conversación específica posee limitaciones debido a la situación y al contexto específico: hay diferencias entre una conversación entre cónyuges y otra entre vecinos, desconocidos, padres, hermanos, jefes, etc. Agregamos, en la conversación con uno u otro de estos interlocutores ocurre, por ejemplo, la elección de una determinada forma pronominal de tratamiento. A propósito, en el contexto del presente trabajo la conversación cotidiana fue un elemento fundamental, dado que a través de un cuestionario se les solicitó a los hablantes de Tunja señalar las formas pronominales empleadas en sus conversaciones diarias y explicar su uso en el marco de la cortesía.

3 Jean Caron (1989, p. 107) indicó que “Las máximas de Grice no pueden, evidentemente, ser consideradas como reglas normativas que definen la forma en que se debe comportar un locutor idealmente cooperativo, ni como presumiendo que la conversación normal se basa (salvo en deplorables excepciones) en un intercambio perfecto entre interlocutores bien intencionados. Se trata, de hecho, de condiciones de posibilidad de la comunicación verbal como tal [...] y no de los principios éticos de una conversación honesta, ni tampoco [...] de las reglas prácticas de una conversación eficaz."
Para Van Dijk, la conversación no es la única forma de interacción oral, también lo son el diálogo pregunta/respuesta entre alumno y profesor, escribir/leer cartas, la entrevista, la discusión, el debate, la asamblea. Aquí nos centramos, además, en la entrevista, puesto que fue a través de esta otra clase de interacción comunicativa que los informantes de la muestra hablaron, y a partir de sus distintos tipos de discurso descubrimos el uso de las formas pronominales de tratamiento de acuerdo con los contextos sociales y los actitudinales (cortesía) en los que se hallaba inmerso el hablante en el momento del acto comunicativo.

En Bravo y Briz (2004), Marta A. Marco sostiene que la modalidad discursiva de la entrevista se distingue esencialmente de la conversación cotidiana en dos rasgos: primero, la toma del turno está predeterminada, pues es el entrevistador el que otorga o cede la palabra; en consecuencia, no existe, en principio, tensión dialógica, de cada pregunta se espera una respuesta. Segundo, una entrevista es una actividad ritualizada, cada participante posee un rol estático, no se pueden intercambiar los papeles de entrevistador y entrevistado.

\section{La cortesía}

La cortesía es un comportamiento humano que está orientado a hacer sentir bien al interlocutor y, además, a que el emisor se sienta bien al generar una expresión cordial. Dentro de nuestro repertorio conversacional hay un buen número de expresiones verbales y no verbales que manifiestan cortesía frente al interlocutor, pero difieren de una cultura a otra e, incluso, de una comunidad de habla a otra. Las fórmulas de cortesía verbal son palabras o frases cortas utilizadas frecuentemente en la vida cotidiana por cualquier hablante de una lengua. Las siguientes son las más empleadas en lengua española por los colombianos, en contextos familiares, sociales, laborales y en la calle: perdón, disculpe, quépena, con todo respeto, por favor, gracias, lo lamento, lo siento, sentido pésame, sintiéndolo mucho, felicitaciones, éxitos, congratulaciones, suerte, mucho gusto, con gusto, encantado( a), ha sido un placer, que Dios lo(a) 
Universidad Pedagógica Nacional

Facultad de Humanidades

bendiga, buenos días, buenas tardes, buenas noches, hasta luego, hasta mañana, que Dios lo(a) lleve con bien, hasta pronto, nos vemos, chao. Además, formas nominales de trato como los diminutivos (Rosita, Pedrito, mijito) y las pronominales (sumercé, tú, usted, vos, su persona). Estas expresiones lingüísticas de cortesía casi siempre van acompañadas de una manifestación no verbal: una sonrisa; una mirada piadosa, comprensiva, de aprobación o de afecto; una palmada en el hombro; un beso en la mejilla; un apretón de manos; un guiño de complicidad; entre otras.

Alonso (1988) apunta que la cortesía es un comportamiento universal, es un requisito ineludible para la convivencia humana; se manifiesta a través del lenguaje verbal y no verbal en todas las sociedades del mundo, aunque sus formas varían de cultura a cultura, de persona a persona, de grupo a grupo y de situación de comunicación a situación de comunicación. Considera que gracias a la cortesía, el hablante es capaz de reconstruir, en alguna medida, las intenciones de sus interlocutores a partir de sus acciones.

Los principios relacionados con la cortesía implican tener en cuenta elementos sociales; es decir, con quién se tiene que ser cortés y con quién no; pero, a nuestro juicio, también inciden factores actitudinales, pues una misma persona algunas veces es cortés y otras no; estos comportamientos los determina el tipo de oyente y su actitud, la naturaleza propia de una situación comunicativa, el contexto espaciotemporal y el estado emocional que acompaña al hablante a la hora de enfrentarse a una interacción oral: mal genio; disgusto con su interlocutor; resentimiento; enfermedad; tristeza; desprecio; alegría, sentimientos de afecto, aprecio, amistad, cariño o amor hacia el oyente; etc. Por ello, indica Alonso, la interacción social implica una lucha constante entre los interlocutores, quienes negocian y equilibran sus necesidades a través de manifestaciones de cortesía, y añadimos, o de descortesía.

La teoría pragmática sobre la cortesía que ha tenido mayor trascendencia ha sido la de Brown y Levinson (1987), de sus planteamientos se subraya que las investigaciones sobre la pragmática de la cortesía han centrado sus objetivos en explicar la variabilidad contextual y cultural en las acciones lingüísticas: qué motivaciones sociales determinan la escogencia de estrategias verbales de cortesía para lograr propósitos comunicativos y qué significados sociales se le atribuyen a esa elección. Para estos dos estudiosos, la cortesía es el comportamiento intencional y estratégico de un individuo, cuyo propósito es satisfacer las necesidades de imagen social, propia y ajena, en los casos en que esta se encuentre amenazada, a través de modos de reparación positivos y negativos que corresponden a lo que denominaron: imagen positiva, o preocupación de un individuo porque los otros piensen bien de él, que consideren que realiza una contribución positiva al mundo social, e imagen negativa, que tiene que ver con el deseo de toda persona de contar con cierto grado de autonomía, o libertad para actuar con el derecho a no ser coercionado; el emisor no debe imponer su voluntad al interlocutor, sino indicarle opciones, con el fin de protegerle la imagen negativa. Lakoff (1973), citado por Haverkate (1994, p. 16), propuso tres estrategias básicas de la cortesía que formuló a manera de máximas, así: "I) No impongas tu voluntad al interlocutor. II) Indica opciones. III) Haz que tu interlocutor se sienta bien; sé amable". De los anteriores planteamientos referidos a la imagen social del individuo se derivan dos tipos de cortesía: positiva y negativa.

Cortesía positiva. Trata de establecer una relación positiva entre los agentes de la interacción comunicativa, toma en cuenta la necesidad de toda persona de gustar y de ser comprendida: deseo de que sus actos sean reconocidos, valorados y aprobados. En palabras de Haverkate (1994):

[...] está basada en el deseo de cada individuo de que otras personas deseen para él lo que él desea para sí mismo; por ejemplo: salud, libertad y honor. Brown y Gilman (1989, p. 162) ilustran el concepto de imagen positiva señalando que la expresión have a nice day (Que tengas/tenga un buen día, Buenos días), que se suele repetir a diario, supone un acto de cortesía que refuerza de un modo característico la imagen positiva del 
interlocutor; el hablante le desea al oyente lo que

desea para sí mismo. (p. 28)

Son otros ejemplos de cortesía positiva las invitaciones, felicitaciones, condolencias, expresiones de gratitud y usos de una determinada forma nominal o pronominal de tratamiento. Este tipo de cortesía se manifiesta también a través de actos no verbales (kinesia y proxemia). La cortesía positiva conlleva la expresión de solidaridad y reconocimiento del otro a través de las siguientes estrategias, entre varias: darse cuenta y atender al oyente; exagerar el interés, la aprobación y la simpatía por el oyente; defender un punto de vista común, ideas y saberes; expresar empatía y optimismo; ser amable y cordial; mostrar cercanía afectiva (amor, cariño, amistad, confianza); expresar humildad al interlocutor; indicarle al oyente que conoce sus problemas y los tiene en cuenta; asumir y afirmar reciprocidad y, si es posible, utilizar la misma lengua, dialecto o jerga. Así, la actitud de negociación y conciliación es una expresión de cortesía positiva. Una muestra característica de este tipo de cortesía es la repetición de las palabras del otro para mostrar solidaridad; por ejemplo:

A: Mi alumno obtuvo una medalla de oro en las

Olimpiadas de Matemáticas

$B$ : ¡Qué maravilloso, una medalla de oro!

Cortesía negativa. Se respeta el derecho de una persona de actuar en libertad, esto significa deferencia. Mediante este tipo de cortesía se intenta conservar la propia individualidad, el deseo de que uno no vea impedidos sus actos, de no sentirse coartado; todos anhelamos no tener obstáculos a nuestras ideas y acciones. Se manifiesta con las siguientes estrategias, entre varias: emplear una determinada forma pronominal de tratamiento para expresar deferencia, condescendencia, cordialidad, humildad, amabilidad; matizar una petición para que aparezca menos transgresora usando un discurso indirecto: "Si no es mucha molestia, ¿me puede prestar el libro? ¿Podría usted cerrar la ventana para que no entre frío?". Haverkate (1994, p. 22) presenta el siguiente ejemplo y su explicación: "Supongamos que el hablante A quiere que el interlocutor $\mathrm{B}$ le pague una factura dentro de un mes"; entonces, "A se dirige a $\mathrm{B}$ de la siguiente manera ¿Podrá usted pagarme la factura dentro de un mes?"; esta oración interrogativa

Representa una manifestación convencional de cortesía exhortativa. Haciendo una pregunta informativa sobre la capacidad de B para realizar el acto pedido, A protege la imagen negativa de aquél, porque da a entender que es consciente de que penetra en el campo intencional de su interlocutor. (p. 23)

Las estrategias "no impongas tu voluntad al interlocutor" (I) e "indica opciones" (II) encajan en lo que se denomina cortesía negativa, y "haz que tu interlocutor se sienta bien; sé amable” (III), en la cortesía positiva. El hablante que respeta las máximas (I) y (II) da a entender al interlocutor que se da cuenta de que amenaza su libertad de acción; es decir, cuando evitamos imponer nuestra voluntad e indicamos opciones estamos expresando un ruego y no un mandato, que es en lo que radica la cortesía exhortativa (negativa).

Los dos tipos de cortesía anteriormente expuestos, positiva y negativa, se tuvieron en cuenta en el análisis de cada una de las tres formas pronominales de tratamiento usadas por los hablantes de Tunja.

\section{Variación en los niveles de la lengua}

Dado que el sistema de la lengua es dinámico, en su uso ocurre la variación lingüística que, según Moreno (2005), es el proceso de cambio que sufre un elemento de la lengua en correlación con factores propiamente lingüísticos y extralingüísticos (sociales, geográficos, psicológicos, históricos, etc.); en otras palabras, es el uso alterno de formas diferentes de decir lo mismo. Al elemento, rasgo o unidad lingüística que puede manifestarse de modos diversos se le denomina variable lingüística. Labov (1983) inició el estudio de las variaciones lingüísticas que se presentan en los distintos niveles de la lengua, denominadas por Moreno (2005) como sociofonéticas, sociogramaticales (sintaxis y mor- 
Universidad Pedagógica Nacional

Facultad de Humanidades

fología), socioléxicas y sociodiscursivas. Aquí nos ocupamos de esta última.

La variación sociodiscursiva se da en el proceso de construcción del discurso y de formación del enunciado, se observa con mayor fuerza en la conversación cotidiana y en los discursos que surgen de otra interacción oral como la entrevista. En estas interacciones verbales es posible hallar muestras relacionadas con factores sociales que inciden en expresiones de diversa índole: saludos, presentaciones, despedidas, agradecimientos, invitaciones, congratulaciones, ofrecimiento de condolencias, preguntas por la salud o por la familia, formas pronominales de tratamiento, etc.

En este trabajo nos enfocamos únicamente en la variación sociodiscursiva de las tres formas pronominales de tratamiento ya referidas, empleadas en el contexto de la construcción y emisión de discursos narrativos, descriptivos, argumentativos y expositivos. Tomar en cuenta los distintos tipos de discurso a los que un hablante puede recurrir es relevante en los estudios sociolingüísticos y pragmalingüísticos, puesto que posibilitan entender las dinámicas sociales y culturales presentes en una comunidad de habla (Calderón, 2011). Aquí definimos esos cuatro tipos de discurso de la siguiente manera:

Narrativo. Consiste en contar, relatar acontecimientos en orden cronológico, tomando en cuenta circunstancias de tiempo, modo, lugar y personas involucradas. El empleo de un discurso narrativo tiene asidero en la necesidad del hablante de dar a conocer su visión de mundo, sus modos de pensar y los imaginarios y arquetipos de su comunidad.

Descriptivo. Centra la atención en mostrar, detallar, presentar una persona, un objeto, un animal o una situación determinada mediante palabras. La descripción es un modo de organización del contenido de un texto en el que se nombra algo con detalles y se le ubica en un espacio y en un tiempo. Una comunidad que describe su entorno demuestra el conocimiento de él y la necesidad de que el interlocutor lo valore de manera positiva.

Argumentativo. Persuade o disuade al interlocutor mediante explicaciones, sustentos, demostracio- nes, comprobaciones (datos estadísticos, testimonios), ejemplos, comparaciones, creencias, vivencias personales y criterios de autoridad. Con la elección de un discurso argumentativo se pretende justificar y defender ante el oyente puntos de vista sobre una situación o un tema específico.

Expositivo: Busca presentar información sobre un tema determinado, transmitirlo y explicarlo a interlocutores que quieren saber sobre él; decir qué es, cómo es y cómo se relaciona con otros elementos de la realidad. Entonces, exponer es explicar con claridad y orden una temática a partir de definiciones, desarrollo de ideas, presentación de datos, explicación de hechos, etc.

\section{Formas pronominales de tratamiento y cortesía}

Moreno (2005) indica que dentro del repertorio conversacional hay un buen número de expresiones verbales que manifiestan cortesía frente a nuestro interlocutor; coincide con estudiosos ya citados aquí, al considerar que estas difieren de una comunidad de habla a otra. La cortesía es uno de los principios de gran trascendencia en el uso social de la lengua, en la interacción comunicativa, y tiene en las formas de tratamiento una de sus más significativas expresiones lingüísticas. Por consiguiente, dentro del ámbito de la cortesía juega un papel preponderante el manejo de determinadas formas pronominales de tratamiento para dirigirnos a un interlocutor; verbigracia, en el contexto hispanohablante se emplean actualmente los pronombres de segunda persona del singular ya citados: tú, vos, usted, sumercé y su persona.

De acuerdo con Cisneros (2005), el uso de pronombres configura un fenómeno lingüístico un tanto complejo en los niveles histórico, morfológico y pragmático. El criterio para la elección de uso de uno de ellos y su valoración pragmática, por parte de los actores de la interacción, depende del contexto sociocultural y comunicativo, del momento histórico y de la tendencia dialectal de los hablantes implicados. En el latín, ya se evidenciaban las oposiciones pragmáticas en el empleo de los pronombres 
de segunda persona singular, puesto que siempre y en toda cultura el hablante recurre al modo más conveniente para conversar con personas de distintos rasgos sociales (edad, género, jerarquía, procedencia, nivel de instrucción, etc.) y, con ello, elige los usos lingüísticos corteses según la circunstancia comunicativa. La mayoría de las lenguas romances, derivadas del latín, conservaron el uso del pronombre vos, como segunda persona del singular, para tratar con respeto a las personas de alta jerarquía política o religiosa. Desde el derrumbamiento del Imperio romano, vos se usó, en alternancia con el pronombre tú, para dirigirse con cortesía a un hidalgo o a un miembro de la familia. Esta alternancia guiada por acuerdos sociales y circunstancias psicoafectivas es quizá la causa de la variación morfológica y la confusión en el uso de estos pronombres; por ejemplo, es frecuente escuchar a un hablante peruano decir "tú me dijistes", en analogía con la conjugación del verbo en segunda persona del plural vosotros dijisteis.

Cisneros expone, además, que en la Edad Media predominaba el voseo como reconocimiento de una autoridad divina y humana, pero se alternaba con el empleo de tú, diferenciando su uso según patrones de género, estatus, afectividad y vínculo familiar, de la siguiente manera: vos de reverencia hacia un interlocutor de alta jerarquía estamental; de distanciamiento social, para dirigirse a personas de estrato inferior; de interés, para tratar a una persona de quien se esperaba un favor, y para dirigirse a las personas de la familia. La forma pronominal tú se usaba de acuerdo con el rango intra/extra-estamental y entre personas unidas por la afectividad.

Ya en el siglo XV, en España, el trato familiar a través del pronombre vos adoptó la forma vuestra merced y el voseo se empleó para tratamientos peyorativos. En el siglo XVI, época dorada de España proclive ya a la decadencia, las formas de tratamiento se complejizaron por la situación social por la que atravesaba y por la coexistencia de uso de tres pronombres de segunda persona singular: tú, vos y vuestra merced - o vuessa merced - para manifestar la familiaridad o no familiaridad, lo formal y lo no formal; aunque la mayor reverencia se dada mediante el uso de vuestra merced y lo no formal, por tú.

Entre los siglos XVI y XVII, la forma vuessa merced se fue transformando, poco a poco, hasta convertirse en usted: vuessa merced > vuesa mestéd > vues-asted $>$ vuestéd $>$ vustéd $>$ usted. Por esa evolución lingüística, se considera que el pronombre usted deviene de vustéd ${ }^{4}$ por aféresis. Luego surge en España el pronombre plural ustedes para un trato familiar, que permanece todavía en Hispanoamérica para sustituir a vosotros/as (este último se conserva aún en España). En el siglo XIX aparece en la Gramática de Andrés Bello, como única forma de pronombre de segunda persona en singular (masculino y femenino), el tú, y para la segunda del plural, vosotros/as. ${ }^{5}$

Respecto del origen de la forma de tratamiento sumercé, consideramos que al llegar el pronombre vuestra merced a América, este sufrió, con el transcurso del tiempo, una transformación: vuestra se reemplazó por el posesivo su y quedó su merced, estos dos vocablos se unieron y formaron sumerced, luego, en un proceso de apócope, se perdió la /d/ final y simultáneamente se acentuó la /é/; así se convirtió en el vocablo agudo sumercé. Actualmente se usa esta forma pronominal en los departamentos de Cundinamarca y Boyacá, Colombia.

Pedroviejo (2004) indica que desde una perspectiva epistemológica, la oposición tú-usted podría enmarcarse dentro de los dos tipos de cortesía propuestos por Brown y Levinson (1987); entonces, el tratamiento de tú encuadraría en la cortesía positiva y el de usted, en la cortesía negativa. Comenta, además, que el uso de tú en el español actual no solamente permea el contexto de las relaciones de parentesco y de amistad, sino que, dado su carácter de marcador de proximidad grupal, traspasa su ámbito de uso a otras esferas donde múltiples atri-

4 En el habla de las personas del campo, del contexto colombiano, observamos que esta forma pronominal ha perdido la $/ d /$ final y se ha acentuado la /e/para convertirse en vusté.

5 Andrés Bello calificó el pronombre usted como algo "enojoso"; es decir, como trato descortés hacia el interlocutor, y extrañamente no contempló el vos. 
Universidad Pedagógica Nacional

Facultad de Humanidades

butos de los interlocutores pueden inducir al empleo de uno de ellos (tratamiento asimétrico) o a ambos (tratamiento simétrico). Señala también que en el mundo hispanohablante se ha incrementado el uso del tú como fórmula de tratamiento adecuado y cortés, y en variados contextos y situaciones de comunicación, como señal del rompimiento de prejuicios $\mathrm{y}$ estratificaciones sociales.

La elección de la forma usted podría representar la pervivencia de normas conservadoras y tradicionalmente más prestigiosas relacionadas con la cortesía negativa, puesto que el uso de usted hace parte de la estrategia denominada por Brown y Levinson (1987) como deferencia con sus dos facetas complementarias: el hablante se inclina ante la superioridad (aparente o ficticia) de su oyente, al que además enaltece. No obstante, el sentido es el mismo: el interlocutor es tratado como un superior y esto en los casos en los que las diferencias de poder entre interlocutores son claras y asumidas por el hablante ubicado en el estadio más bajo de la escala social (relación asimétrica), y en los casos donde se impone una deferencia recíproca se da la relación simétrica.

Navarro (2004) relata que en el primer tercio del siglo XVI, en España, el pronombre vos indicaba una relación de solidaridad entre los cortesanos, un trato simétrico (de igual a igual) mientras que para el "muy inferior" se empleaba el pronombre tú. En esa época, se establecía el siguiente paradigma en el uso cortesano:

Vuestra merced había de ser la fórmula de máximo respeto y formalidad, pues vos es el tratamiento de solidaridad entre iguales, mientras que tú, que era el tratamiento general entre la gente llana, pasa a ser utilizado por esos "hombres cultos" como trato asimétrico de inferioridad; pero para el pueblo en general, el trato de solidaridad debía ser tú, mientras vos y vuestra merced eran tratos más o menos formales, pero insolidarios y asimétricos. (pp. 217-218)

Años más tarde, en España el tuteo se empleó, y se emplea aún, para referirse a los muchachos y menores de la familia, así como para el trato íntimo afectivo.

\section{Variables sociales que rigen las formas pronominales de tratamiento}

La elección de una forma pronominal de tratamiento para dirigirse a otra persona está determinada por la cortesía positiva y la negativa, dos dimensiones actitudinales guiadas por múltiples circunstancias de tipo social. Entre las variables sociales que rigen el empleo de dichas formas se destacan, entre otras, género, edad, nivel de instrucción, procedencia y estatus (Moreno, 2005). Para los fines de esta investigación, según se expuso ya, tomamos las formas sumercé, usted y tú, y caracterizamos su uso a partir de las variables de género, edad y nivel de instrucción, que ostenta el hablante (emisor).

El género influye al elegir una forma de tratamiento; así, en algunas comunidades de habla son las mujeres las que más utilizan el pronombre tú para dirigirse a otras mujeres y a los hombres, y en otras, no es usual el tratamiento de tú entre hombres. En las comunidades de habla donde hay variación en el uso de pronombres, la edad incide a la hora de seleccionar una determinada forma de tratamiento; verbigracia, en la interacción nieto-abuelo, abuelonieto; entre vecinos: el de mayor edad frente al menor y viceversa; en esas situaciones comunicativas entran en juego, además, otros elementos como la afectividad, la autoridad, la distancia social, la condescendencia, los estados emocionales y la deferencia determinada por factores como el poder y el estatus, entre otros.

El nivel de instrucción es un factor que determina el uso de cualquier forma pronominal de tratamiento; entre hablantes con formación académica alta es posible hallar el uso predominante del tú, pero un hablante de esa condición puede dirigirse a uno de nivel de instrucción bajo con el pronombre usted; como se afirmó ya, todo está supeditado a los diversos aspectos que confluyen también, como la relación de familia, la amistad, la confianza, la procedencia, la costumbre, etc. Cabe aclarar que cualquier forma pronominal de tratamiento que se utilice sí está regida por una amplia gama de variables sociales. 
En suma, las reflexiones teóricas hasta aquí expuestas constituyen el marco que fundamentó e iluminó el camino de la presente investigación.

\section{Metodología}

Formas pronominales de tratamiento y cortesía en el habla de Tunja, Colombia fue una investigación de tipo descriptivo-explicativo que combinó los enfoques cuantitativo y cualitativo, puesto que se levantaron datos estadísticos que mostraron la frecuencia de uso de cada una de las formas de tratamiento sumercé, usted y tú; se analizó dicha infor- mación y se interpretó a la luz de la teoría sobre la cortesía (positiva y negativa) planteada por Brown y Levinson (1987) y resignificada por Haverkate (1994); igualmente, se identificó y se explicó el uso de dichas formas pronominales, en relación con la cortesía, a partir de la emisión de discursos narrativos, descriptivos, argumentativos y expositivos. Ahora se describe cada una de las tres variables sociales elegidas para conformar el grupo de informantes de quienes se obtuvieron los materiales de habla -Género, edad (Generación, G) y nivel de instrucción $(\mathrm{N})$-:

Tabla 1. Variables sociales

Género Edad Nivel de instrucción

\begin{tabular}{|c|c|c|c|c|c|c|c|}
\hline Mujeres & Hombres & G1 & G2 & G3 & N1 & N2 & N3 \\
\hline 27 & 27 & 20-34 & Primaria & Secundaria & Superior \\
\hline
\end{tabular}

Ahora bien, la muestra recogida en el sector urbano de Tunja fue la siguiente:

Tabla 2. Muestra

\begin{tabular}{|c|c|c|c|c|c|c|}
\hline \multirow[t]{2}{*}{ Variables sociales } & \multicolumn{2}{|c|}{ Generación 1} & \multicolumn{2}{|c|}{ Generación 2} & \multicolumn{2}{|c|}{ Generación 3} \\
\hline & Mujer & Hombre & Mujer & Hombre & Mujer & Hombre \\
\hline Nivel de instrucción 1 & 3 & 3 & 3 & 3 & 3 & 3 \\
\hline Nivel de instrucción 2 & 3 & 3 & 3 & 3 & 3 & 3 \\
\hline Nivel de instrucción 3 & 3 & 3 & 3 & 3 & 3 & 3 \\
\hline
\end{tabular}

Para un total de 54 hablantes. Este tamaño de la muestra superó el parámetro de 25 hablantes por cada 100.000 habitantes recomendado por Moreno $(2005)^{6}$. Los materiales lingüísticos se recolectaron a través de dos instrumentos 7 : la encuesta (cuestionario) ${ }^{8}$ y la entrevista semidirigida.

6 Según datos del DANE, Tunja, capital del departamento de Boyacá, cuenta con una población estimada para el año 2013 en 181.407 habitantes.

7 Se utilizaron los materiales del Proyecto para el Estudio Sociolingüístico del Español de España y de América, (zona Tunja), recopilados por un grupo de estudiantes de la Escuela de Idiomas de la Universidad Pedagógica y Tecnológica de Colombia, dirigido por Donald F. Calderón Noguera. Ver página www.preseea.tunja.co

8 www.linguas.net/preseea. Confróntese el texto Cuestionario sobre las formas de tratamiento en: http://www.linguas.net/LinkClick.aspx?fileticket $=$ pNLOEGOSGVI $\% 3$ D \& tabid $=474 \&$ mid $=949$ 
Universidad Pedagógica Nacional

Facultad de Humanidades

\section{Encuesta a partir de pregunta directa}

Se reitera que para el diseño del cuestionario se siguieron los lineamientos trazados por PRESEEA, cuya intención fue la de plasmar en ese instrumento elementos que influyen en el uso de una determinada forma de tratamiento a interlocutores varios (familia, amigos, compañeros, jefes, subalternos, desconocidos). En este instrumento, los informantes indicaron la forma pronominal (sumercé, usted o tú) empleada, en el contexto de conversaciones cotidianas, para dirigirse a: padre, madre, hermano/a, hijo/a, primo/a, tío/a, sobrino/a, pareja, cuñado/a, amigo/a, compañero/a de estudio o de trabajo, jefe/a, subalterno/a y personas desconocidas, señalando la explicación de su uso: cercanía afectiva —amor, cariño, amistad, confianza-, lejanía afectiva — deferencia, cordialidad, condescendencia, humildad, amabilidad-.

\section{Entrevista semidirigida}

Se apoyó en centros de interés o temas diversos y cotidianos, a saber: clima, barrio, vecinos, vivienda, la ciudad, la gente que vive en Tunja, problemas de la ciudad, familia y amistad, profesión y trabajo, esparcimiento, costumbres y deseo de mejorar económicamente. Estas temáticas indujeron a los hablantes a producir, de manera espontánea y relajada, discursos narrativos, descriptivos, argumentativos y expositivos que permitieron identificar la variación sociodiscursiva de las tres formas pronominales de tratamiento mencionadas y relacionar su uso con la cortesía.

Las entrevistas se grabaron en la casa del informante, en privado, para su comodidad y tranquilidad. A cada entrevista asistieron dos investigadores de campo: uno formuló las preguntas y el otro tomó notas relacionadas con aspectos lingüísticos y sociales; cada entrevista duró 40 minutos. El siguiente fue el procedimiento abordado para el desarrollo de la presente investigación:

- Recolección de materiales: selección de hablantes, observación, construcción de notas y diarios de campo, diseño y aplicación de los cuestionarios, grabación de entrevistas semidirigidas y su transcripción mediante el sistema TEI. ${ }^{9}$

- Lectura y revisión de los 54 cuestionarios y las 54 entrevistas semidirigidas.

- Organización de los materiales por género, edad y nivel de instrucción.

- Tabulación de la información contenida en los cuestionarios para determinar la frecuencia de uso de las formas pronominales de tratamiento (sumercé, usted y tú), a partir de las tres variables sociales determinadas.

- Descripción, análisis y explicación del funcionamiento de la cortesía a través del uso de dichas formas pronominales de tratamiento, tomando en cuenta las variables sociales elegidas.

- Identificación de la variación sociodiscursiva de las tres formas pronominales de tratamiento, en el contexto de discursos narrativos, descriptivos, argumentativos y expositivos, y análisis cualitativo de la relación del uso de esas tres formas de tratamiento con la cortesía.

\section{Análisis y discusión de resultados}

\section{Materiales de encuesta (cuestionario)}

Para el análisis de los materiales recolectados mediante encuesta se establecieron las siguientes categorías de interlocutores: Familia (F), Amigos (A), Compañeros (C), Superiores (S), subalternos (s) y Desconocidos (D), sobre la base de las tres variables sociales precitadas: género, edad y nivel de instrucción. Además de indicar la frecuencia de uso de las tres formas pronominales de tratamiento, dicho uso se analizó desde la teoría de la cortesía (positiva y negativa) propuesta por Brown y Levinson (1987) y resignificada por Haverkate (1994). A continuación se presenta, en cuatro tablas, los datos obtenidos:

9 The Text Encoding Initiative. 
Tabla 3. Frecuencia de uso de las formas pronominales según edad y nivel de instrucción de las mujeres

\begin{tabular}{l|c|c|c}
$\begin{array}{l}\text { Forma } \\
\text { pron. }\end{array}$ & $\begin{array}{l}\text { Generación y } \\
\text { Nivel de ins- } \\
\text { trucción }\end{array}$ & $\begin{array}{l}\text { Interlocu- } \\
\text { tor }\end{array}$ & $\%$ \\
\hline \multirow{3}{*}{ Sumercé } & G3: N1 & F & 85,6 \\
& & C, S, S, D & 14,4 \\
\hline \multirow{3}{*}{ Usted } & G1: N1 & F & 79 \\
& G1: N2 & S & 8,7 \\
& & D & 8,3 \\
\hline \multirow{4}{*}{ Tú } & G2: N3 & F & 44 \\
& & C & 33 \\
\hline
\end{tabular}

De acuerdo con la tabla 3, el uso de sumercé se da con mayor frecuencia en las mujeres de la tercera generación con un nivel bajo de formación académica (85,6\%); usted, en las mujeres más jóvenes también con estudios primarios y en las que acreditan educación secundaria (79\%); y tú, en las mujeres de edades entre 35 y 54 años con formación universitaria (44\%). Aquí se observa una escala ascendente de uso de las tres formas regida por la formación académica de las mujeres: sumercé se ubica en el lugar más bajo (estudios primarios); en el medio, usted (estudios primarios y secundarios); y en el más alto, tú (estudios superiores); así, el nivel de instrucción de las mujeres tunjanas determina la frecuencia de uso de esta última forma pronominal de tratamiento.
Tabla 4. Frecuencia de uso de las formas pronominales según edad y nivel de instrucción de los hombres

\begin{tabular}{|c|c|c|c|}
\hline Forma pron. & $\begin{array}{l}\text { Generación y } \\
\text { Nivel de instruc- } \\
\text { ción }\end{array}$ & Interlocutor & $\%$ \\
\hline Sumercé & G1: N3 & $\begin{array}{c}F \\
A, C, S, S, D\end{array}$ & $\begin{array}{r}40 \\
0\end{array}$ \\
\hline Usted & G2,G3:N1 & $\begin{array}{l}F \\
D \\
C \\
A \\
S \\
S\end{array}$ & $\begin{array}{c}57 \\
21,6 \\
10,7 \\
7,1 \\
2,6 \\
1\end{array}$ \\
\hline Tú & G1: N2 & $\begin{array}{c}\text { F } \\
\text { A } \\
\text { C } \\
\text { D } \\
\text { S, S }\end{array}$ & $\begin{array}{r}35 \\
35 \\
20 \\
10 \\
0\end{array}$ \\
\hline
\end{tabular}

En la tabla 4, se observa que el empleo de sumercé ocurre en los hombres más jóvenes con educación superior (40\%), pero solo para dirigirse a los miembros de su familia. El uso de usted se da con mayor frecuencia entre los hombres de 35 a más de 55 años de edad con educación primaria, para tratar a la familia $(57 \%) \mathrm{y}$, en proporciones menores para dirigirse a otras personas. El uso del pronombre tú se escucha en los hombres más jóvenes con educación secundaria, para el trato a los familiares y a los amigos (35\%). Nótese que estos hablantes jóvenes alternan sumercé y tú para dirigirse a su familia, y nunca usan usted. En resumen, las formas sumercé y tú son utilizadas por los hombres más jóvenes con formación académica media y alta, y usted, por los mayores con nivel de instrucción bajo. 
Universidad Pedagógica Nacional

Facultad de Humanidades

Tabla 5. Frecuencia de uso de las formas pronominales de tratamiento en el habla de las mujeres tunjanas y explicación de dicho uso

\begin{tabular}{|c|c|c|c|c|c|c|}
\hline Forma & $\begin{array}{l}\mathbf{F} \\
\%\end{array}$ & $\begin{array}{l}\text { A } \\
\%\end{array}$ & $\begin{array}{l}\mathrm{C} \\
\%\end{array}$ & $\begin{array}{l}\mathbf{S} \\
\%\end{array}$ & $\begin{array}{l}\mathbf{S} \\
\%\end{array}$ & $\begin{array}{l}\text { D } \\
\%\end{array}$ \\
\hline Sumercé & $\begin{array}{c}57,5 \\
\text { amor, cariño }\end{array}$ & $\begin{array}{c}28 \\
\text { cordialidad, cariño }\end{array}$ & $\begin{array}{c}3 \\
\text { amabilidad }\end{array}$ & $\begin{array}{c}8,5 \\
\text { humildad, } \\
\text { cortesía }\end{array}$ & $\begin{array}{c}2 \\
\text { Amabilidad }\end{array}$ & $\begin{array}{c}1 \\
\text { cortesía }\end{array}$ \\
\hline Usted & $\begin{array}{c}40 \\
\text { condescendencia }\end{array}$ & $\begin{array}{c}4 \\
\text { condescendencia }\end{array}$ & $\begin{array}{c}20 \\
\text { condescendencia }\end{array}$ & $\begin{array}{c}20 \\
\text { deferencia }\end{array}$ & $\begin{array}{c}2 \\
\text { Condescendencia }\end{array}$ & $\begin{array}{c}14 \\
\text { condescendencia }\end{array}$ \\
\hline Tú & $\begin{array}{c}35 \\
\text { amor, cariño }\end{array}$ & $\begin{array}{c}25 \\
\text { confianza }\end{array}$ & $\begin{array}{c}24 \\
\text { confianza }\end{array}$ & 0 & $\begin{array}{c}10 \\
\text { Confianza }\end{array}$ & $\begin{array}{c}6 \\
\text { amabilidad }\end{array}$ \\
\hline
\end{tabular}

La tabla 5 indica claramente lo siguiente: la forma pronominal más usada por las 27 mujeres de la muestra es sumercé ( $57.5 \%$ ) seguida de usted (40 $\%)$, y la que menos emplean es tú (35\%); en todos los tres casos, para tratar a los miembros de su familia. En porcentajes significativos usan sumercé (28\%) y tú $(25 \%)$ para dirigirse a los amigos.

La explicación de uso de sumercé la apoyan en razones de amor, cariño, amabilidad y humildad; de usted, para expresar condescendencia o deferencia (respeto), y de tú, para manifestar amor, cariño, confianza y amabilidad; así, las mujeres tunjanas emplean el tuteo para dirigirse a padres, abuelos, hijos, nietos, cónyuges, jóvenes y menores de la familia como trato íntimo afectivo. Es evidente que las formas sumercé y tú son para las mujeres, expresiones de cercanía afectiva que encuadran en lo denominado cortesía positiva, basada en el "deseo de cada individuo de que otras personas deseen para él lo que él desea para sí mismo" (Haverkate, 1994, p.28); es decir, en este caso, para hacer sentir bien a los integrantes de la familia. La forma usted connota una leve distancia afectiva (respeto, o deferencia); por ello, se enmarca dentro de la cortesía negativa. En conclusión, las mujeres tunjanas alternan, mediante el uso de las tres formas pronominales de tratamiento, los dos tipos de cortesía planteados por Brown y Levinson (1987) y resignificados por Haverkate (1994).

Tabla 6. Frecuencia de uso de las formas pronominales de tratamiento en el habla de los hombres tunjanos y explicación de ese uso

\begin{tabular}{|c|c|c|c|c|c|c|}
\hline Forma & $\begin{array}{l}\mathrm{F} \\
\%\end{array}$ & $\begin{array}{l}\mathrm{A} \\
\%\end{array}$ & $\begin{array}{l}\mathrm{C} \\
\%\end{array}$ & $\begin{array}{l}S \\
\%\end{array}$ & $\begin{array}{l}S \\
\%\end{array}$ & $\begin{array}{l}\mathrm{D} \\
\%\end{array}$ \\
\hline Sumercé & $\begin{array}{c}38 \\
\text { cercanía afectiva }\end{array}$ & $\begin{array}{c}30 \\
\text { cortesía }\end{array}$ & $\begin{array}{c}20 \\
\text { amabilidad }\end{array}$ & $\begin{array}{c}6 \\
\text { humildad, } \\
\text { cortesía }\end{array}$ & $\begin{array}{c}4 \\
\text { Amabilidad }\end{array}$ & $\begin{array}{c}2 \\
\text { amabilidad }\end{array}$ \\
\hline Usted & $\begin{array}{c}42 \\
\text { Deferencia }\end{array}$ & $\begin{array}{c}31 \\
\text { condescendencia }\end{array}$ & $\begin{array}{c}10 \\
\text { condescendencia }\end{array}$ & $\begin{array}{c}10 \\
\text { deferencia }\end{array}$ & $\begin{array}{c}4 \\
\text { condescendencia }\end{array}$ & $\begin{array}{c}3 \\
\text { deferencia }\end{array}$ \\
\hline Tú & $\begin{array}{c}30 \\
\text { amor, cariño }\end{array}$ & $\begin{array}{c}28 \\
\text { confianza }\end{array}$ & $\begin{array}{c}22 \\
\text { confianza }\end{array}$ & $\begin{array}{c}2 \\
\text { Amistad }\end{array}$ & $\begin{array}{c}12 \\
\text { confianza }\end{array}$ & $\begin{array}{c}6 \\
\text { amabilidad }\end{array}$ \\
\hline
\end{tabular}


La tabla 6 muestra que la forma pronominal más empleada por los 27 hombres elegidos es usted (42\%), seguida de sumercé (38\%) y la que menos emplean es tú (30\%); en todos los casos, para el trato familiar. Con frecuencias significativas, los hombres usan usted (31\%) y tú (32\%) para tratar a sus amigos. En general, sustentan la explicación del uso de usted en razones de deferencia y condescendencia (cortesía negativa); de sumercé, por cercanía afectiva, humildad y amabilidad (cortesía positiva); respecto del uso de tú, coinciden en su explicación con las mujeres: por amor, cariño, confianza y amistad. Los datos expuestos en esta tabla revelan que el porcentaje más alto de uso se da en la forma pronominal usted, para dirigirse a los miembros de la familia.

La elección del pronombre usted podría estar representando la pervivencia de normas conservadoras y tradicionalmente más prestigiosas, relacionadas con la cortesía negativa, puesto que, como ya se expuso, el uso de usted hace parte de la estrategia denominada por Brown y Levinson (1987) como deferencia. En suma, los hombres tunjanos también alternan, a través del uso de las formas pronominales de tratamiento, los dos tipos de cortesía abordados aquí.

$\mathrm{Al}$ consolidar los resultados registrados en las tablas 5 y 6 , se concluye que la forma pronominal más utilizada por los 54 hablantes de Tunja es sumercé ( $57,5 \%$ por mujeres y $38 \%$ por hombres) seguida de usted ( $40 \%$ por mujeres y $42 \%$ por hombres) y de tú ( $35 \%$ por mujeres y $30 \%$ por hombres). Así, es evidente un uso alterno de las tres formas, y las mayores frecuencias ocurren para dirigirse a la familia. Se destaca que según la explicación de uso dada por los informantes, los tunjanos emplean sumercé y tú para manifestar cortesía positiva y usted, cortesía negativa.
El siguiente gráfico ilustra lo anterior de manera más clara:

Gráfico 1. Frecuencia de uso de formas pronominales de tratamiento en la comunidad de habla de Tunja.

Interlocutor: familia

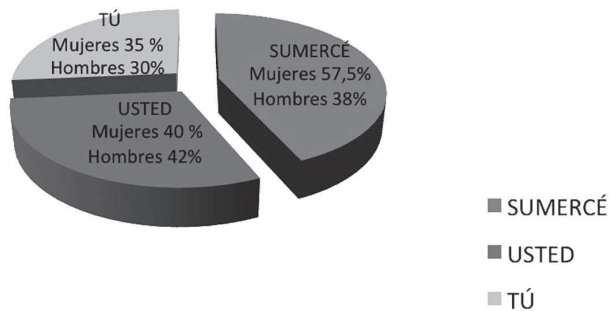

Con el anterior análisis se corrobora que la cortesía, tanto positiva como negativa, es un requisito ineludible para la convivencia humana (Alonso, 1988); sus manifestaciones varían de persona a persona, dependiendo del género, la edad o el nivel de formación académica del hablante (emisor) y, sin duda, los principios relacionados con la cortesía implican tener en cuenta variables sociales.

\section{Materiales de entrevista}

Mediante el análisis del corpus conformado por 57 entrevistas semidirigidas se identificaron cuatro tipos de discursos (narrativos, descriptivos, argumentativos y expositivos) a los cuales recurrieron los informantes inscritos en las tres variables sociales (género, edad y nivel de instrucción). En sus intervenciones, observamos también el uso alterno de las formas pronominales de tratamiento sumercé, usted y tú, hallazgo que se analizó de manera cualitativa, igualmente, con el apoyo en la teoría referida a la cortesía positiva y negativa. Véase una muestra de cada tipo discursivo: 
Universidad Pedagógica Nacional

Facultad de Humanidades

\section{Discurso narrativo}

A la solicitud "Cuénteme una situación donde usted haya sentido dolor", la mujer informante - G2, N2narró lo siguiente:

A raíz de la muerte de mi madre y mi papi pues consiguió una señora, pero nosotros, pues al principio sí, pues lo apoyamos y le dijimos pues papi si usted quiere estar bien, si es para el bien de sumercé pues consiga alguien que lo quiera, pero pues él consiguió una persona que tal vez no es $[\ldots]$

En su narración, la hablante recuerda un episodio familiar, trágico y problemático; para relatarlo emplea el pronombre usted como indicador de cortesía negativa, ya que expresa deferencia y condescendencia con la decisión que tomó su padre; respeta el derecho de él de actuar en libertad, dado su estado de viudez; intenta conservarle su propia individualidad, no impedirle sus actos, no coartarlo. Pese a que la decisión del padre no fue compartida por la hija, ella aplica una estrategia básica de cortesía, propuesta por Lakoff (1973): "No impongas tu voluntad al interlocutor". Además, de modo alterno, usa sumercé en señal de cortesía positiva, puesto que la informante toma en cuenta la necesidad de su padre de ser comprendido: deseo de que su decisión sea reconocida, valorada y aprobada; por ello, le dijo: "Si es para el bien de sumercé pues consiga alguien que lo quiera, $[\ldots]$ ".

\section{Discurso descriptivo}

A la pregunta “ $¿$ Te habría gustado que fuera distinta la ciudad de Tunja?, ¿ ¿cómo?", una informante -G2, N3- describe así:

Me gustaría que algunas cosas cambiaran pero $\mathrm{mmm}$ me gustaría que/ que existieran sitios de recreación, que crearan como más atractivos, que el plan no solo sea ir a Unicentro o solo ir a dar una vuelta por Centro Norte, sino otros planes, de pronto, sitios donde tú te puedas recrear.

Como el entrevistador tutea a su entrevistada, esta elige la misma forma pronominal de tratamiento para describir los posibles cambios de la ciu- dad, como signo de cortesía positiva, pues ese uso de tú conlleva una manifestación de solidaridad; la informante asume y afirma reciprocidad frente a su entrevistador, mediante el tratamiento simétrico y como fórmula de trato adecuado y cortés hacia una persona desconocida (Pedroviejo, 2004).

\section{Discurso argumentativo}

A la pregunta “'Siempre dicen que la gente de Boyacá no se relaciona con los demás?, ¿cómo es esa relación?", un informante - G2, N1- refuta esa apreciación argumentando de la siguiente manera:

No, mire usted/ yo por la verda [verdad] que por ese sentido si me siento orgulloso y contento porque a mí me estiman mucho en el barrio, creo que sumercé misma se dio cuenta ayer porque todo el mundo pasa y me saluda.

El hombre informante emplea inicialmente la forma usted anticipando una actitud deferente (cortesía negativa) antes de controvertir la crítica de la que se siente aludido, pero luego, para sustentar su punto de vista emplea la forma sumercé como manifestación de amabilidad y afecto (cortesía positiva); pone en práctica esta máxima de Lakoff (1973): "Haz que tu interlocutor se sienta bien; sé amable". A pesar de que la pregunta contiene un alto nivel de agravio colectivo y personal, el informante alterna las dos formas de cortesía para contra-argumentar y defender su capacidad de relacionarse con los miembros de su comunidad, indicando como evidencia las propias percepciones de su entrevistadora, estrategia argumentativa que introduce mediante el marcador discursivo de causa porque, que le permite construir el razonamiento para convencerlo de lo contrario y, así, desmentir eso que "dicen" de "la gente de Boyacá".

\section{Discurso expositivo}

A la pregunta “¿Qué piensa de sus compañeros revolucionarios, de todos los paros que están haciendo?", un hombre - G2, N3 - contesta:

Pues yo pienso que, hay unos que apoyo/ pero hay otros que no/ generalmente usted sabe que siempre que hay algo así, ahí hay política. 
El informante expone su punto de vista sobre el tema referido a los "compañeros revolucionarios" y a "los paros" 10 usando la forma usted para involucrar a su interlocutor en el tema y recordarle que él también conoce esa problemática; de este modo, genera una relación permeada por la lejanía afectiva (respetuosa) frente a su interlocutor. La elección de la forma usted, por parte del hablante entrevistado, responde a normas conservadoras y tradicionalmente más prestigiosas relacionadas con la cortesía negativa, puesto que el uso de usted, reiteramos, constituye la estrategia denominada deferencia. Observamos que entre el informante y el entrevistador se da una relación simétrica, el segundo emplea, implícitamente, también la forma usted, lo que se deduce de la expresión “¿Qué piensa [...]”; entonces, se establece una deferencia recíproca.

En síntesis, hombres y mujeres de Tunja usan las tres formas pronominales de tratamiento en la construcción de discursos verbales narrativos, descriptivos, argumentativos y expositivos, siempre en una actitud cordial. Con los hallazgos expuestos, podemos corroborar y parafrasear lo planteado por Francisco Moreno (2005): la variación lingüística es el proceso de cambio que sufre un elemento de la lengua en correlación con factores propiamente lingüísticos y extralingüísticos; es el uso alterno de formas diferentes de decir lo mismo, pero, en este caso, con intenciones enmarcadas en la cortesía positiva o en la negativa. Insistimos en que el análisis de los distintos discursos de los hablantes es fundamental en los estudios sociolingüísticos y pragma-lingüísticos, dado que permite entender las dinámicas sociales y culturales presentes, por ejemplo, en la comunidad de habla de Tunja. A través de las muestras analizadas conocimos: la manera como resuelven los problemas familiares; sus juicios valorativos sobre la ciudad donde viven; sus percepciones sobre la infraestructura de la ciudad y sobre los que constantemente lideran las huelgas, o paros; y el comportamiento (actitud cortés) del hablante tunjano en el contexto de la interacción comunicativa.

10 En Colombia, "paros" significa huelgas o ceses de actividades de trabajadores, de estudiantes, de campesinos, etc.

\section{Conclusiones}

El análisis de los datos recogidos mediante las encuestas arrojó lo siguiente:

\section{Forma pronominal sumercé}

Los porcentajes más altos de uso de esta forma pronominal de tratamiento se dan en las mujeres de mayor edad con estudios primarios $(85,6 \%) \mathrm{y}$, en menor proporción, en los hombres jóvenes con educación superior (40\%). Aglutinados todos los datos por género se evidenció que son las mujeres, de diversas edades y distintos niveles de formación académica, quienes utilizan con mayor frecuencia la forma sumercé $(57,5 \%)$ frente a los hombres (30 $\%)$; tanto ellas como ellos, para dirigirse a los miembros de la familia y hacerlos sentir bien, con lo cual se corrobora lo propuesto por Haverkate (1994, p.28) a propósito de la cortesía positiva: "Deseo de cada individuo de que otras personas deseen para él lo que él desea para sí mismo". Notamos que este resultado coincide con los hallazgos del trabajo de Peralta (2006) en la comunidad de habla de PaipaBoyacá, pues allí se expone que esta fórmula se emplea con mayor frecuencia para dirigirse a los abuelos, padres y tíos.

\section{Forma pronominal usted}

Los porcentajes más altos de empleo de este pronombre ocurren en las mujeres jóvenes con bajo grado de escolaridad (69\%) y en los hombres maduros con educación secundaria (57 \%); en ambos casos, para el trato familiar. Agrupados todos los datos por género y realizado el análisis cuantitativo correspondiente se observó que son los hombres, de distintas edades y diferentes niveles de instrucción, quienes usan con mayor frecuencia la forma usted (42\%) frente a las mujeres (40\%). Todos los informantes apoyaron la explicación del uso en el respeto y la condescendencia hacia el interlocutor. El uso de usted, por parte de los hablantes de Tunja, demuestra el reconocimiento de normas conservadoras e históricamente de mayor renombre, relacionadas con la cortesía negativa. 
Universidad Pedagógica Nacional

Facultad de Humanidades

\section{Forma pronominal tú}

La forma pronominal tú es más utilizada por las mujeres entre los 35 y 54 años con educación superior (44 \%) y por los hombres jóvenes con estudios superiores (35\%). Unificados los datos por género hallamos que el pronombre tú lo usan en mayor proporción las mujeres (35\%) que los hombres (30\%), en ambos casos, para el trato a la familia. Hallamos, además, que el grado de escolaridad de las mujeres tunjanas determina el tuteo: a mayor nivel de instrucción, mayor uso de esta forma pronominal de tratamiento. El trato de tú transmite al interlocutor cercanía afectiva (amor, cariño, amistad y confianza); encuadra en lo denominado cortesía positiva, que busca establecer una excelente relación entre los agentes de la interacción comunicativa.

En suma, de acuerdo con el análisis de la variación lingüística de las formas pronominales de trato interpersonal de los hablantes tunjanos, se puede afirmar que la más usada es sumercé seguida de usted y de tú; las tres variables lingüísticas ocurren, en frecuencias mayores, para expresar sentimientos y actitudes corteses hacia la familia. Así, hemos logrado el primer objetivo orientado a determinar la frecuencia de uso de las formas pronominales de tratamiento cortés sumercé, usted y tú, según variables sociales de género, edad y nivel de instrucción del hablante tunjano, y explicar ese uso en el contexto de la cortesía.

Respecto de la variación sociodiscursiva, evidente en las entrevistas semidirigidas, se halló que los hablantes tunjanos alternan el uso de esas tres formas pronominales de tratamiento cortés en el contexto de discursos narrativos, descriptivos, argumentativos y expositivos; veamos:

En el discurso narrativo, la informante usa la forma usted como indicador de cortesía negativa, pues expresa deferencia y condescendencia con la decisión de su padre (contraer matrimonio nuevamente con una mujer que es de poco agrado para la hija); ella preserva la propia individualidad de su padre, no obstaculiza esa decisión; pese a no estar de acuerdo con la elección de la pareja, asume esta estrategia básica de cortesía: "No impongas tu volun- tad al interlocutor" (Lakoff, 1973). Además, simultáneamente emplea sumercé en señal de cortesía positiva: ella sabe que su padre necesita ser comprendido, él espera que sus decisiones sentimentales sean reconocidas, valoradas y aprobadas por su familia, especialmente, por sus hijos.

En el discurso descriptivo, la informante trata de tú a su interlocutor (entrevistador), dado que él formula la pregunta con tuteo “ ¿Te habría gustado [...]"; ella expresa cortesía positiva asumiendo y afirmando reciprocidad, mediante el tratamiento simétrico, como fórmula de trato adecuado y cordial hacia una persona que no conoce (Pedroviejo, 2004).

En el discurso argumentativo, el informante utiliza, en un primer momento, el pronombre usted para manifestar una actitud deferente (cortesía negativa) antes de rebatir la crítica que encierra la pregunta de la entrevistadora, pero en un segundo momento, usa sumercé para defender su toma de posición de manera afectuosa y amable (cortesía positiva); recurre a la máxima "Haz que tu interlocutor se sienta bien; sé amable" (Lakoff, 1973). En suma, el hablante alterna esas dos formas de cortesía para contra-argumentar y defender su tesis.

En el discurso expositivo, el informante expone su propia opinión sobre el tema referido a "los compañeros revolucionarios" y "los paros" empleando el pronombre usted, con el fin de inmiscuir a su interlocutor en el asunto objeto de la pregunta y, a su vez, recordarle que él también tiene conocimiento de ello; de este modo, crea una relación permeada por la lejanía afectiva (respetuosa). La escogencia de esta forma pronominal de tratamiento muestra la intención del hablante, en su exposición, de aplicar una estrategia conservadora y prestigiosa concomitante con la cortesía negativa.

De este modo, alcanzamos nuestro segundo objetivo encaminado a describir las variaciones sociodiscursivas de las formas pronominales sumercé, usted y tú, en el contexto de discursos narrativos, descriptivos, argumentativos y expositivos, y explicar la relación de ese uso con las manifestaciones de cortesía positiva y negativa. 
Finalmente, se corroboró que la cortesía, expresada mediante formas pronominales de tratamiento, es el comportamiento intencional y estratégico de un individuo, cuyo propósito es satisfacer las necesidades de imagen social, propia y ajena, en los casos en que esta se encuentre amenazada, a través de modos de reparación positivos y negativos (Brown y Levinson, 1987).

Con este estudio del uso de formas pronominales de trato cortés en la comunidad de habla de Tunja, Boyacá, Colombia, estamos contribuyendo a visibilizar la riqueza expresiva de hablantes hispanoamericanos y, además, hemos presentado el aporte de la variación sociolingüística de dichas formas a la vigencia de la lengua española.

\section{Referencias bibliográficas}

Alonso, R. (1988). Competencia comunicativa y cortesía. Cuestiones metodológicas. En ASELE, Actas I. Centro virtual Cervantes. Recuperado el 10 de julio de 2013 de

http://cvc.cervantes.es/ensenanza/biblioteca_ele/asele/ pdf/01/01_0191.pdf

Bravo, D. (ed.) (2005). Estudios de la (des)cortesía en español. Categorías conceptuales y aplicaciones a corpora orales y escritos. Estocolmo-Buenos Aires: editorial Dunken.

Bravo, D. y Briz, A. (eds.) (2004). Pragmática sociocultural: estudios sobre el discurso de cortesía en español. Barcelona: Ariel Lingüística.

Brown, P. y Levinson, S. (1987). Politeness. Some universal en language use. Cambridge: Cambridge University Press.

Brown, R. y Gilman A. (1989). Politeness theory and Shakespeare's four major tragedies. Language and society, 18, 159-212.

Calderón, D. (2011). El español hablado en Tunja. Materiales para su estudio. Tunja: Universidad Pedagógica y Tecnológica de Colombia.

Caron, J. (1989). Las regulaciones del discurso. Psicolingüística y pragmática del lenguaje. Madrid: Editorial Gredos.

Cisneros, M. (2005). Grados de cortesía en el uso de pronombres personales de segunda persona singular. Proximidad, situación comunicativa y momento histórico. En D. Bravo, Estudios de la (des)cortesía en español. Categorías conceptuales y aplicaciones a corpora orales y escritos. Estocolmo-Buenos Aires: editorial Dunken.

Haverkate, H. (1994). La cortesía verbal. Estudio pragmalingüístico. Madrid: Editorial Gredos.

Labov, W. (1983). Modelos sociolingüísticos. Madrid: Cátedra.

Lakoff, R. (1973). The logic of politeness; or, minding your p's and q's. Papers from the Regional Meeting, 9, 292-305.

Marco, M. (2004). Cortesía en diferentes situaciones comunicativas. La conversación coloquial y la entrevista sociológica semiformal. En D. Bravo y A. Briz (eds.), Pragmática sociocultural: estudios sobre el discurso de cortesía en español. Barcelona: Ariel Lingüística.

Moreno, F. (2005). Principios de sociolingüística y sociología del lenguaje [2ª ed.]. Barcelona: Ariel Lingüística.

Navarro, R. (2004). Formas de cortesía en la Segunda Celestina. En D. Bravo y A. Briz (eds.), Pragmática Sociocultural: estudios sobre el discurso de cortesía en español. Barcelona: Ariel Lingüística.

Peralta M., C. (2006). "Sumercé" una forma de tratamiento usada por niños, jóvenes y adultos del municipio de Paipa-Boyacá. Recuperado el 3 de mayo de 2013 de http://claudinaperaltamartinez.blogspot. com/2006/11/dialectologa.html

Pedroviejo, J. (2004). Formas de tratamiento en dos obras de teatro del siglo xx: Historia de una Escalera y Bajarse al Moro. En D. Bravo y A. Briz (eds.), Pragmática sociocultural: estudios sobre el discurso de cortesía en español. Barcelona: Ariel Lingüística.

Portolés, J. (2007). Pragmática para hispanistas. Madrid: Editorial Síntesis.

Poyatos, F. (1994). La comunicación no verbal [3 vol.]. Madrid: Istmo.

Van Dijk, T. (1983). La ciencia del texto. Barcelona: Paidós. Tusón, A. (1997). Análisis de la conversación. Barcelona: Ariel. 